\title{
Development of an Integrated Electro-mechanical Energy Conversion System to Support Undergraduate Electrical Engineering Curriculum
}

\author{
Dr. Kenan Hatipoglu, West Virginia University Insttitute of Technology
}

Kenan Hatipoglu is an assistant professor at Department of Electrical and Computer Engineering at West Virginia University Institute of Technology. He completed his Master of Science degree in Electrical Engineering at University of Louisville, Kentucky in 2008 and joined Tennessee Tech University in 2009 to pursue his Ph.D. in Electrical (Power) Engineering. He completed his graduate study in August 2013. He received his Bachelor's degree in Electrical Education from Department of Electrical Education in Faculty of Technical Education and Technology Engineering at Marmara University, Istanbul, Turkey in 2005. His current research interests include smartgrid and microgrid applications, power system control, renewable energy resources, power electronics and engineering education .

Dr. Mingyu Lu, West Virginia University Institute of Technology

Mingyu Lu received the B.S. and M.S. degrees in electrical engineering from Tsinghua University, Beijing, China, in 1995 and 1997 respectively, and the Ph.D. degree in electrical engineering from the University of Illinois at Urbana-Champaign in 2002. From 1997 to 2002, he was a research assistant at the Department of Electrical and Computer Engineering in the University of Illinois at Urbana-Champaign. From 2002 to 2005, he was a postdoctoral research associate at the Electromagnetics Laboratory in the University of Illinois at Urbana-Champaign. He was an assistant professor with the Department of Electrical Engineering, the University of Texas at Arlington from 2005 to 2012. He joined the Department of Electrical and Computer Engineering, West Virginia University Institute of Technology in 2012, and he is currently an associate professor. His current research interests include wireless power transmission, radar systems, microwave remote sensing, antenna design, and computational electromagnetics. He was the recipient of the first prize award in the student paper competition of the IEEE International Antennas and Propagation Symposium, Boston, MA in 2001. He served as the chair of Antennas and Propagation Society of IEEE Fort Worth Chapter from 2006 to 2011.

\section{Dr. Afrin Naz, West Virginia University Institute of Technology}

Dr. Afrin Naz is an assistant professor at the Computer Science and Information Systems department at West Virginia University Institute of Technology. She is working with high school teachers to inspire the K-12 students to the STEM fields. In last four years Dr. Naz and her team launched six workshops for high school teachers. Currently her team is training the high school teachers to offer online materials to supplement their face-to-face classroom.

\section{Dr. Yogendra M. Panta, West Virginia University Institute of Technology}

Dr. Panta is an Assistant Professor of mechanical engineering at West Virginia University Institute of Technology. His research area is in fluid thermal science, and Computational Fluid Mechanics. Panta received M.S. in Mechanical Engineering from Youngstown State University, and a Ph.D. Mechanical Engineering from University of Nevada Las Vegas.

\section{Steven Kent Blevins, West Virginia University Institute of Technology}

Steven Blevins is currently a senior majoring in electrical engineering at West Virginia University Institute of Technology. He is currently working as an electrical engineering intern, and will be graduating with a Bachelor's of Science in Electrical Engineering with a minor in Mathematics in December 2017. 


\section{Development of an Integrated Electro-mechanical Energy Conversion System to Support Undergraduate Electrical Engineering Curriculum}

\section{Introduction}

As the underlying technology of many vital industries such as electric vehicles and wind turbines, electro-mechanical energy conversion is an important topic of the undergraduate engineering programs. The objective of this paper is to demonstrate the development of an integrated electro-mechanical energy conversion system and further, to engage undergraduate students to learn and investigate electro-mechanical energy conversion systems, assemble a motor/generator from parts, optimize the motor/generator configuration, and visualize its performance. The system is capable of demonstrating more than 50 realistic motor and generator configurations. In each mode, the system can be further reconfigured to various motor and generator architectures, such as series DC motors, shunt DC motors, compound DC motors, AC motors, single-phase generators, and three-phase generators. The electro-mechanical energy conversion system is comprised of four major components: (i) a reconfigurable machine, (ii) an actuator with built-in sensors, (iii) a programmable controller, and (iv) a data collector. These four components are coordinated by a personal computer, such that the system performance can be controlled and visualized in real time. The electro-mechanical system is used primarily to support the undergraduate curricula of three departments at the West Virginia University Institute of Technology (WVU Tech), including Electrical and Computer Engineering Department, Mechanical Engineering Department, and Computer Science Department. This project is highly inter-disciplinary. It involves four faculty members. The expertise of the faculty members is complementary to each other and covers all the aspects of this project. The four faculty members collaborate to build and test the system, and also integrate it in undergraduate curricula. This project therefore established an excellent platform for collaborative efforts in three departments, and it inspires numerous innovative ideas across disciplinary boundaries. The integrated electro-mechanical energy conversion system has been constructed in September 2016 and is currently under various tests.

\section{Relevant work}

A dissectible machine is a very helpful tool that can be used to help students learn certain course related information. It is a visual aid tool used to demonstrate the construction of different types of machines. For some students it may be difficult to fully grasp the concept behind the theories taught in the class without having some sort of a device that can demonstrate it. Dissectible machines enhance the learning of students by giving them a visual representation of information taught in the classroom.

There are many colleges and universities that use dissectible machines in teaching required coursework for electrical engineering students. Among them are West Virginia University (WVU), Ohio State University (OSU), Indian Institute of Technology Bombay (IIT Bombay), University of North Carolina at Charlotte (UNC-Charlotte), and Tri-State University, Indiana. 
Each of these colleges and universities, and many more, use dissectible machines to aid students in the learning process of the field of electrical engineering.

At WVU, there are two required courses related to electrical power systems for undergraduate students. The two courses are related to transformers, rotating machines and basic power system analysis. There are also four elective courses offered at the undergraduate level that pertain to power. The power engineering laboratory at WVU is used in the instruction of the two required power systems related courses for electrical engineering students as well as for research purposes. In the power engineering laboratory at WVU, there is a dissectible machine set that consists of an electrical machines tutor, test kit, and control panel. The machines tutor kit consists of multiple different components used in the construction of different electrical machines. The test kit includes a variable-speed drive motor which is used as the prime mover for the test machine, a prony brake dynamometer, and rotatable brushgear. Finally, the control panel is made up of two independent power supplies used to power the test machine, and an appropriate number of voltmeters and ammeters ${ }^{1}$.

Also, at WVU, dissectible transformers are available. A three-legged core with separate coils is available to provide either 56, 115, or $230 \mathrm{Vac}$ and a low amount of dc voltages. Interchanging of the coils is permitted. Core gap-spacers are also provided to allow for choke or reactor operations $^{1}$.

WVU believes that the dissectible machine set and the dissectible transformer provide students obtain a good understanding of the construction of different types of ac and dc machines as well as how the different ac and dc machines work. By actually constructing the devices, students achieve a hands-on experience from the dissectible machine set and dissectible transformer. WVU believes that students gain more knowledge and are motivated more by working with the dissectible machine set and dissectible transformer ${ }^{1}$.

At OSU, junior electrical engineering students are required to take a course pertaining to energy conversions and power systems which is taught in lecture form and laboratory form. There are also several electives related to electrical power offered to students at OSU. A key feature in the electrical power department at OSU is the High Voltage Laboratory. Students participate in two courses that take place in the High Voltage Laboratory. The first course is primarily dedicated to safety and measurement of quantities. The second course provides for more involved experiments. A few experiments in the second course involve surge generators. The surge generators are all in-house design and construction. Therefore, the design information pertaining to the surge generators are available for teaching purposes. This gives students a visual tool to observe exactly how certain devices are constructed ${ }^{2}$.

Also at OSU, dissectible machines are used in the energy conversion lab. The test machines are fully dissectible and can be used to construct a wide variety of ac and dc electrical machines. This allows students the opportunity to observe the behavior and construction of various kinds of ac and dc machines ${ }^{2}$.

At IIT Bombay, laboratory instruction is offered and believed to be a necessary part of the electrical engineering curriculum. The laboratory instruction is divided into three parts consisting 
of student experimentation, instructor demonstrations, and field visits. Student experiments deal primarily with digital and analog instrumentation to show that text book theory is not always achieved in the practical world. While students perform their experiments, design aspects of the machines being used are discussed. Instructor demonstrations allow for more complex experiments and student demonstrations. They usually pertain to exciting phenomena, procedures, or technologies. IIT Bombay offers students a hands-on visual tool for learning as well as the traditional lecture style teaching ${ }^{3}$.

At UNC-Charlotte, a power engineering education laboratory has been recently constructed. The purpose of this laboratory is to provide a practical application of the theories taught in the classroom to students. This laboratory is used for multiple power related courses taught at UNCCharlotte. Among the inventory of experimental configurations in the laboratory is a dissectible machines system. The purpose of offering students with the opportunity to work with such a device is to present students a chance to configure and test various types of electrical machines. By giving students this unique opportunity, UNC-Charlotte believes that they are providing students with an excellent opportunity to increase in the knowledge of power related topics of the electrical engineering discipline ${ }^{4}$.

At Tri-State University, Indiana students are also provided with the opportunity to work with a dissectible machines system. The dissectible machines system here is designed to help students in their studies of electrical machine theory. It complements the theory taught in the classroom. The student responses to this feature of Tri-State University are all positive. By repeating measurements, calculations, etc. students can compare the output powers and various other parameters of electrical machines. Overall, the dissectible machines system at Tri-State University has been very beneficial to students ${ }^{5}$.

\section{Objective of the system integration}

As the underlying technology of many vital industries such as electric vehicles and wind turbines, electro-mechanical energy conversion is an important topic of the undergraduate engineering programs. The objective of this paper is to demonstrate the development of an integrated electro-mechanical energy conversion system and further, to engage undergraduate students to learn and investigate electromechanical energy conversion systems, assemble a motor/generator from parts, optimize the motor/generator configuration, and visualize its performance. The integrated system is expected to significantly enrich the undergraduate curricula of three departments at WVU Tech, including Electrical and Computer Engineering Department, Mechanical Engineering Department, and Computer Science Department.

Electro-mechanical energy conversion is covered by the curricula of both Electrical Engineering and Mechanical Engineering at WVU Tech. The Power Laboratory of WVU Tech has a number of instruments manufactured by LabVolt to demonstrate fundamental concepts of electromechanical energy conversion. However, none of the existing instruments has the capability of allowing students to assemble a motor/generator from parts, optimize the motor/generator configuration, and visualize its performance. Compared with the existing instruments, the new electro-mechanical system is highly versatile and flexible. It enables students to have hands-on experience with various types of electro-mechanical system and control/measure their 
performance in real time. Thus, access to the system is anticipated to enhance the students' learning effectiveness tremendously.

The system is used primarily to support the undergraduate education of WVU Tech and it is used very often. Every student in the Electromechanical Energy Conversion Systems course conducts extensive experiments with this system. Meanwhile, this system is used to demonstrate electrical/mechanical concepts in many courses such as Engineering Electromagnetics, Power Plant Engineering, and Components and Circuits Design. Also, this system is open to all students of the College of Engineering and Sciences (with approximately 500 registered students in total) for their independent study and/or senior design projects.

\section{The electro-mechanical energy conversion system components}

As its name indicates, the electro-mechanical energy conversion system can be configured in two modes: motor mode (conversion from electrical energy to mechanical energy) and generator mode (conversion from mechanical energy to electrical energy). In each mode, the system can be further reconfigured to various motor/generator architectures, such as series DC motors, shunt DC motors, compound DC motors, AC motors, single-phase generators, and three-phase generators. In total, the system is capable of demonstrating more than 50 realistic motor/generator configurations.

The electro-mechanical energy conversion system is depicted in Figure 1. It is comprised of four major components:

(i) A reconfigurable machine;

(ii) An actuator with built-in sensors;

(iii) A programmable controller;

(iv) A data collector.

These four components are coordinated by a personal computer, such that the system performance can be controlled and visualized in real time.
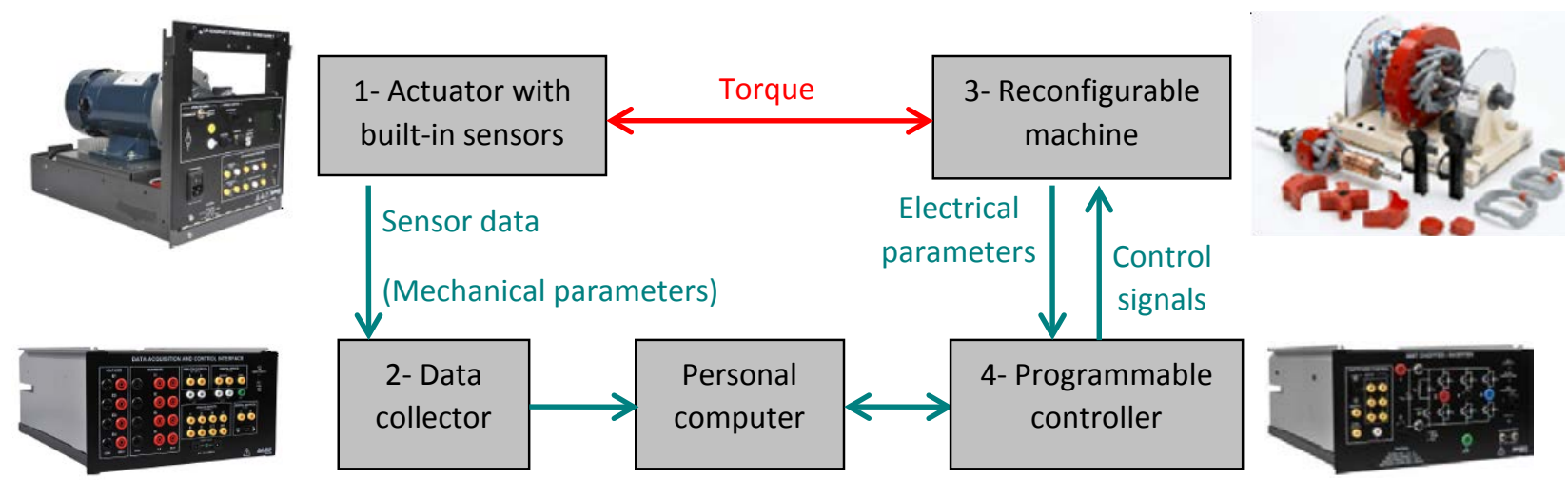

Figure 1: Illustration of the electro-mechanical energy conversion system.

The reconfigurable machine ${ }^{6}$ in Figure 1 is the core component of the system. Manufactured by Feedback Instruments with model number 62-100, it is designed to offer the utmost reconfigurability. As shown by an inset photograph in Figure 1, it includes a large number of 
field poles, interpoles, armature poles, stators, rotors, and coils, which can be assembled to emulate various realistic motor or generator configurations. The reconfigurable machine is coupled with the actuator by mechanical means. To be specific, the actuator provides driving torque to the reconfigurable machine in the generator mode, and in the motor mode the actuator behaves as a load of the reconfigurable machine. The actuator includes multiple torque sensors and speed sensors that convert the mechanical parameters to electrical format. The sensor data is passed to the personal computer through the data collector. The programmable controller in Figure 1 is the interface between the personal computer and reconfigurable machine. It receives digital commands from the personal computer, converts the commands to high-voltage/highcurrent control signals, and supplies the control signals to control the reconfigurable machine. The programmable controller also measures various electrical parameters (voltage, current, impedance, etc.) of the reconfigurable machine and delivers the measurement data to the personal computer. Over the personal computer, a specialized software named LVDAC-EMS is required to control the reconfigurable machine and display measurement data in real time. LVDAC-EMS is compatible with various programming software including Matlab and Labview. In this project, the actuator, data collector, programmable controller, and software development kit were purchased from Amtek Inc.

\section{Implementation of the Integrated System}

The final integrated electromechanical energy conversion system can be seen at Figure 2. All the required system components were put together on a Lab Station with necessary connections. Components are numbered and will be explained as the following.

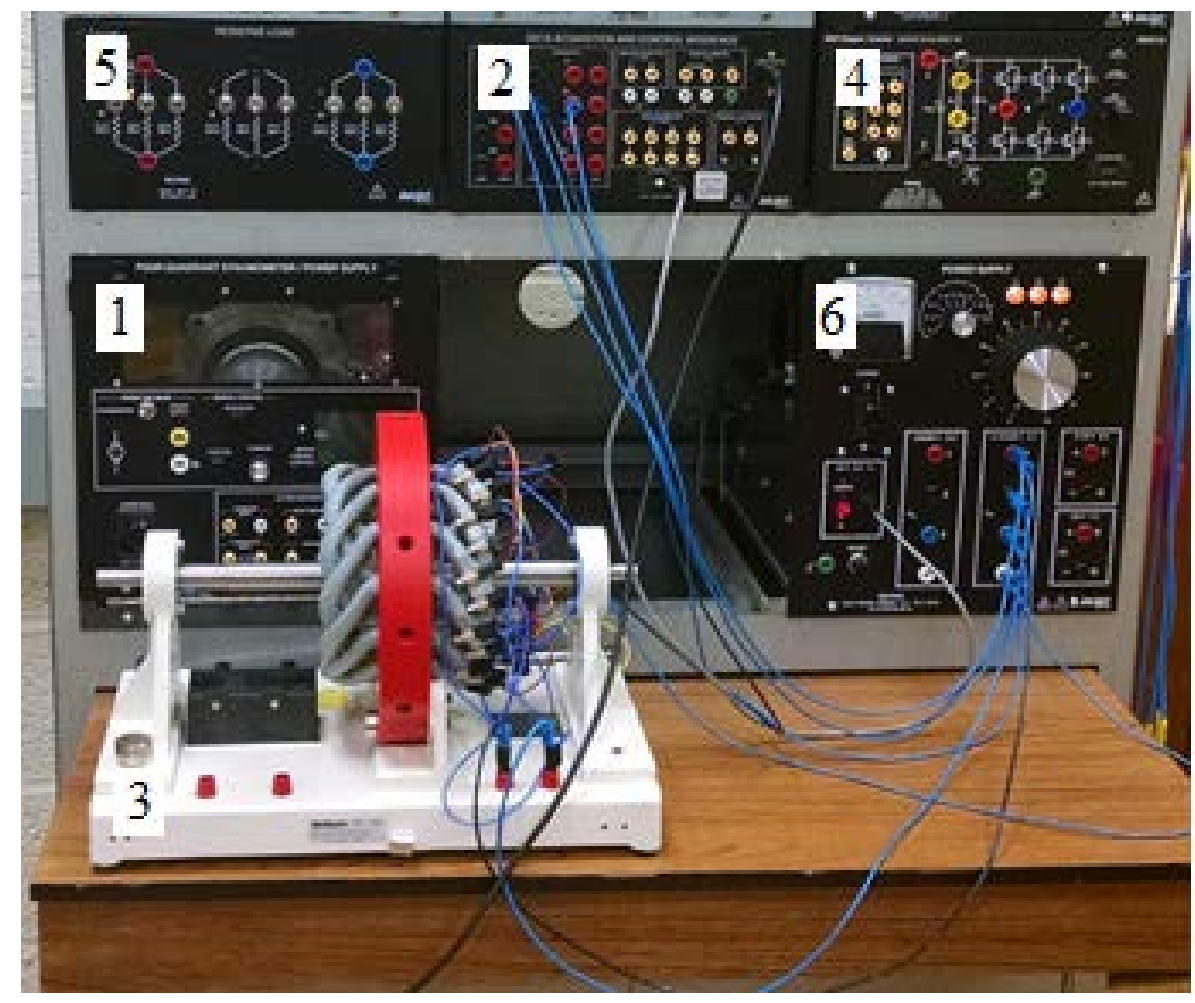

Figure 2: Implementation of the electro-mechanical energy conversion system 


\section{1- Actuator:}

The actuator ${ }^{7}$ is a highly versatile USB peripheral designed to be coupled with the reconfigurable electro-mechanical machine. Two operating modes are available: Dynamometer and Power Supply. A wide variety of user-selectable functions are available in each operating mode. In the Dynamometer mode, the unit becomes a four-quadrant dynamometer that can act as either a fully configurable brake (i.e., a mechanical load) or a fully configurable prime mover (i.e., a motor drive). In the Power Supply mode, the unit becomes a four-quadrant power supply that can act as a dc voltage source, dc current source, ac power source, etc. In each operating mode, key parameters related to the selected function are displayed. Speed, torque, mechanical power, and energy are displayed in the Dynamometer mode while voltage, current, electrical power, and energy are displayed in the Power Supply mode.

Two modes are available to control the function which the Four-Quadrant Dynamometer/Power Supply performs: Manual and Computer-Based. In the Manual control mode, the module operates as a stand-alone unit, and the function performed is selected, set, and monitored using front-panel mounted controls and display. This mode provides access to all basic functions. In the Computer-Based control mode, the function performed by the module is selected, set, and monitored using the computer software. In this mode, communication between the FourQuadrant Dynamometer/Power Supply and the host computer running the computer software is achieved through a USB connection? ${ }^{7}$.

\section{2- Data collector:}

The Data Acquisition and Control Interface (DACI) ${ }^{8}$ is a versatile USB peripheral used for measuring, observing, analyzing, and controlling electrical and mechanical parameters of the actuator and the programmable controller. For these purposes, a set of computer-based instruments as well as a variety of control functions are available for the DACI. The provided instruments include voltmeters, ammeters, power meters, frequency meters, efficiency meters, impedance meters, power factor meters, energy meters, torque and speed meters, an oscilloscope, a phasor analyzer, a harmonic analyzer, and a spectrum analyzer. The DACI and software also allow manual and timed data recording. The recorded data can be saved to files in any specified location, graphically represented with the provided graph plotting tool, and exported into a spreadsheet application ${ }^{8}$.

\section{3- Reconfigurable electromechanical machine:}

It is the main component of the system. It is a fully functional, multi-part constructional machine which creates a practical and realistic electro-mechanical machine operation. Over 50 types of electro-mechanical machines can be assembled such as DC and AC (single and three-phase) motors and generators. It allows machine construction to be examined with a high level of electrical and mechanical safety. Portable machine and system components provide flexibility. The separate field poles, interpoles, armature poles, hub, 12-slot stator and squirrel cage rotor are made from electrical steel laminations riveted together. The coils are wound from synthetic enamel-covered copper wire and wrapped with a strong cloth-base tape. Each has 'coil finish' and identification bands. A stainless steel shaft of high corrosion resistance is supported by plain 
and self-aligning ball race bearings. These are held in aluminum alloy housings fixed to a cast aluminum baseplate. The shaft speed can range from very low values up to 3,600 rev/min (ac machines), or 5,000 rev/min (dc machines) according to the application. The commutator, slip rings and brush gear are of simple design to facilitate armature assembly and give good accessibility ${ }^{6}$.

The following studies and machines assemblies may be investigated ${ }^{6}$ :

- Introduction to electromagnetism

- Machine operating principles

- $\quad$ AC and DC generators/motors

Machines with and without interpoles:

- DC series motor

- DC compound motor

- DC shunt motor

- DC shunt generator

- DC series generator

- DC compound generator

- DC separately excited generator

- Single phase AC induction motor, squirrel cage, 2 pole and 4 pole

- Single phase AC series universal motor

- Single phase AC repulsion motor

- Single phase AC synchronous motor/generator, 2 pole and 4 pole

- Single phase AC generator, rotating field

- Single phase AC generator, rotating armature
- 3-phase ac induction motor, squirrel cage,

2 pole and 4 pole

- 3-phase ac synchronous motor, 2 pole

- 3-phase ac synchronous generator, 2 pole

- AC brushless generator

- Stepper motors

- Shaded pole induction motor

- Split field series motor

- Dynamic braking of a DC motor

- Power factor correction of AC motors

- Synchronization

- Synchronous motor characteristics

- Pole-changing induction motor

- DC shunt motor faults

- 4 pole induction motor faults

\section{4- Programmable controller:}

It is an IGBT Chopper/Inverter module ${ }^{9}$ that controls the speed, frequency and torque of the reconfigurable electro-mechanical machine. It consists of seven insulated-gate bipolar transistors (IGBT). Six IGBTs are used to implement choppers and inverters. These IGBTs are protected against a variety of abnormal operating conditions, such as short-circuits, overvoltage, overcurrent, and overheat. The seventh IGBT and a dumping resistor allow smooth dissipation of excess energy at the dc bus. The dumping circuit can be activated through the use of a toggle switch on the front panel. The module switching control section allows $0 / 5 \mathrm{~V}$ pulse signals from the DACI. The signals are input in the IGBT Chopper/Inverter module through a nine-pin connector. Six miniature banana jacks can be used as test points to monitor the pulse signals using an oscilloscope. These jacks can also be used to inject 0/5 V pulse signals from an alternate control unit, as well as to inhibit each gating circuit. The IGBT Chopper/Inverter module also includes a synchronization output to trigger an oscilloscope when observing the switching control signals, as well as a switching control disable input that allows all six IGBTs in the chopper/inverter section to be switched off ${ }^{9}$. 


\section{5- Load:}

In order to test the system under realistic conditions, loads are required to be connected to the dissectible machine. The one used on the Lab Station is a Resistance Module block form LabVolt (EMS 8311) ${ }^{10}$.

\section{6- Power Supply:}

The electro-mechanical system needs a special three-phase power supply, as its electric current consumption is estimated to be as much as 6-Amp. Main Power Source used in system integration is from LabVolt (EMS 8821 Power Supply Module) ${ }^{11}$. It is a 3-Phase power supply that is capable of producing 120 / $208 \mathrm{Vac}$ and 120Vdc. Therefore, the system is hosted in the Power Laboratory of Electrical and Computer Engineering Department at WVU Tech, which is equipped with three-phase 120 -Volt/208-Volt 12-Amp receptacle power outlets. In addition, safety training is required for any person who intends to operate the system.

\section{7- Personal Computer, Monitor and Computer software:}

A Personal Computer, as shown by an inset photograph in Figure 3, is directly connected to the DACI and allows users to work with LVDAC-EMS software to manage the recordings of the DACI and to control the Programmable controller and Actuator. The Monitor shown in Figure 3 is used to project all possible Graphical User Interfaces (GUIs) that DACI, Programmable controller and Actuator offer. Those GUIs are numbered in Figure 3 and their names are given as follows.
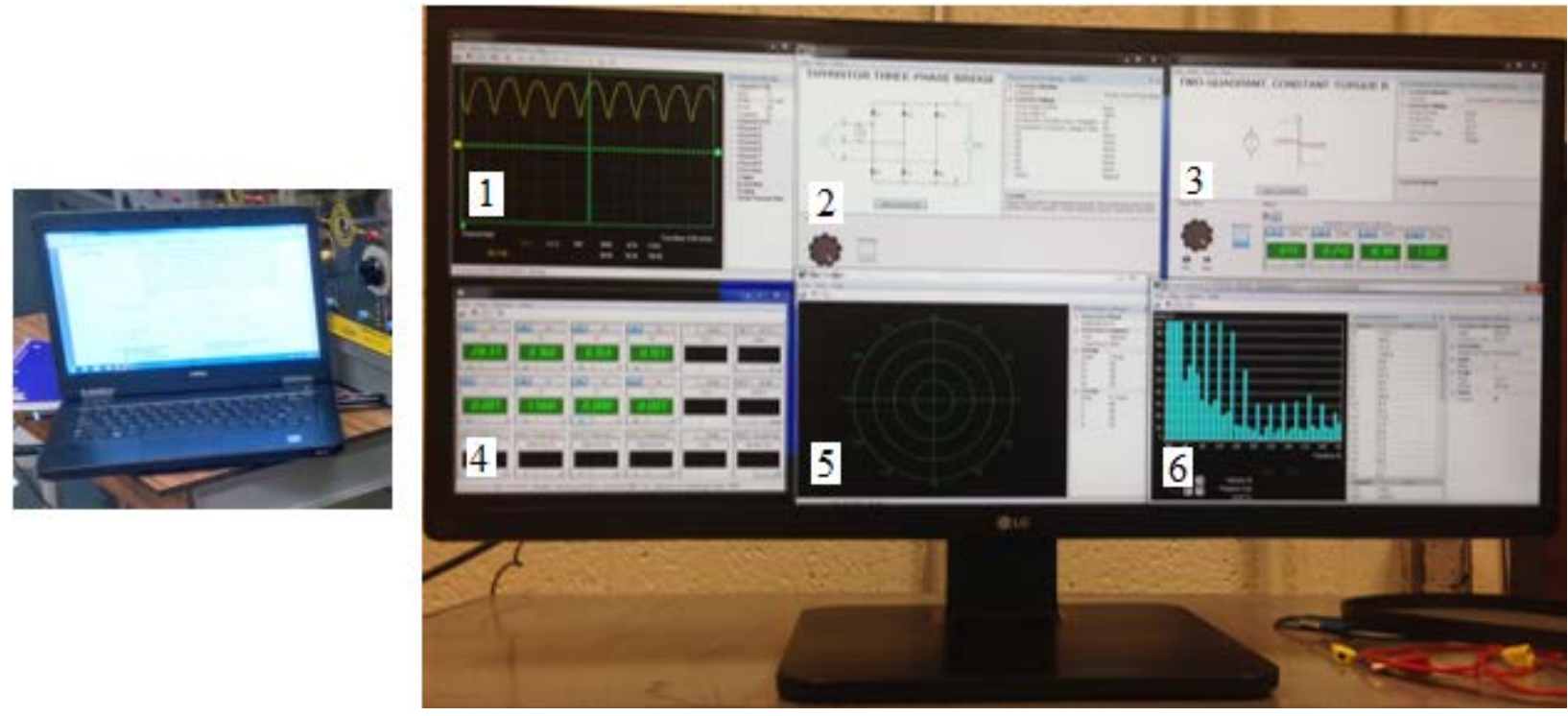

Figure 3: Personal Computer and Monitor used

1- Oscilloscope

2- GUI for Programmable controller

3- GUI for Actuator
4- Multimeter

5- Phasor Analyzer

6- Harmonic Analyzer 
The software is a user-friendly tool that facilitates the use of the various functions which can be implemented with the DACI, and actuator. It offers the possibility to control various inputs and outputs of the DACI using third-party rapid prototyping software like Mathworks ${ }^{\circledR}$ MATLAB, National Instruments ${ }^{\circledR}$ LabVIEW, and other programming tools that support Microsoft ${ }^{\circledR}$.NET Framework 3.5. Software gives users the possibility to build their own advanced functions using the DACI.

\section{Configuration and Testing}

As it has been mentioned before, the electro-mechanical energy conversion system can be configured in two modes: motor mode (conversion from electrical energy to mechanical energy) and generator mode (conversion from mechanical energy to electrical energy). In each mode, the system can be further reconfigured to various motor/generator architectures, such as series DC motors, shunt DC motors, compound DC motors, AC motors, single-phase generators, and threephase generators. In total, the proposed system is capable of demonstrating more than 50 realistic motor/generator configurations. Figure 4 shows some sample configurations of the Dissectible machine built as DC and AC Motor/Generator (a and b respectively) and also as classroom demonstrations (c) on fundamental concepts of electro-mechanical energy conversion. The inset photograph (d) in Figure 4 shows how the dissectible machine was coupled with the actuator for generator and motor testing. The dissectible machine's shaft was modified to accommodate the belt. Various tests were done on various system configurations and system integrity was sustained on all of them. Optimization of the motor/generator configuration, and performance visualization were achieved through using programmable controller, actuator with built-in sensors and data recorder thru the personal computer.

\section{Integration into the curriculum}

Thanks to its inter-disciplinary nature, the system can be integrated into a wide range of undergraduate courses in three departments: Electrical and Computer Engineering Department, Mechanical Engineering Department, and Computer Science Department. As a far from complete list, the system will facilitate the teaching in Electromechanical Energy Conversion Systems (EE 335), Alternative Energy Resources (EE 434), Introduction to Power Electronics (EE 435), Engineering Electromagnetics (EE 345), Power Plant Engineering (MAE 407), Components and Circuits Design (MAE 440), and Principles of Programming Language (CS 310).

On the basis of this project, faculty will actively seek other funding sources to upgrade the current system. By further incorporating solar panels and fuel cells, the system can be extended to emulate smart grid systems. Faculty members plan to submit this idea to the Major Research Instrumentation (MRI) program of the National Science Foundation (NSF). The system aims to improve the undergraduate education at WVU Tech. It will also enable faculty to submit proposals to the Transforming Undergraduate Education in Science, Technology, Engineering and Mathematics (TUES) program and Improving Undergraduate STEM Education (IUSE: EHR) program of the NSF. Moreover, the PIs of this project will request funding from NASAWV Space Grant Consortium to develop a new inter-disciplinary course based on the electromechanical system. Currently, undergraduate student who works on this project received West 


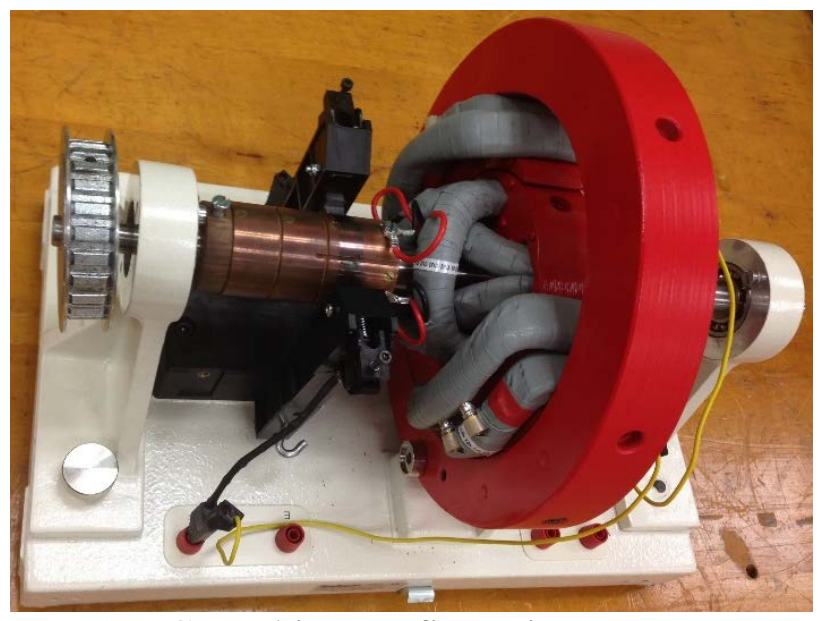

(a) DC machine configuration

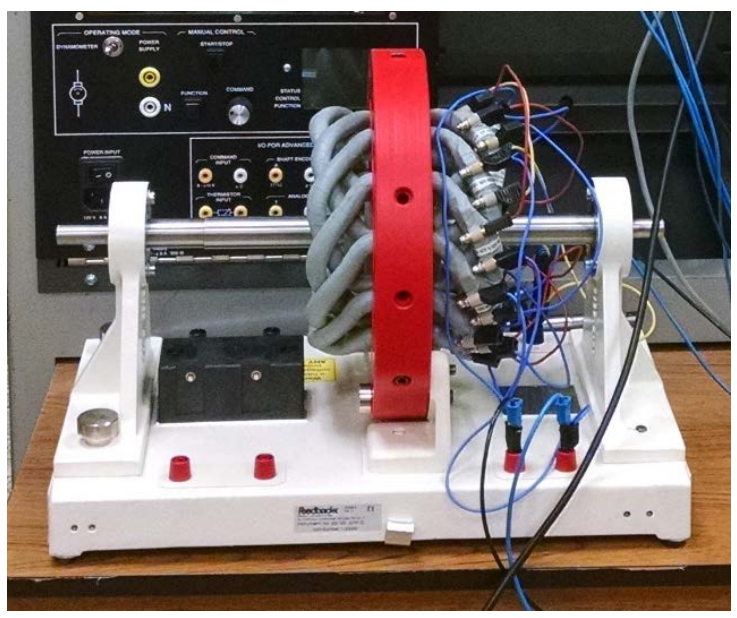

(b) AC machine configuration

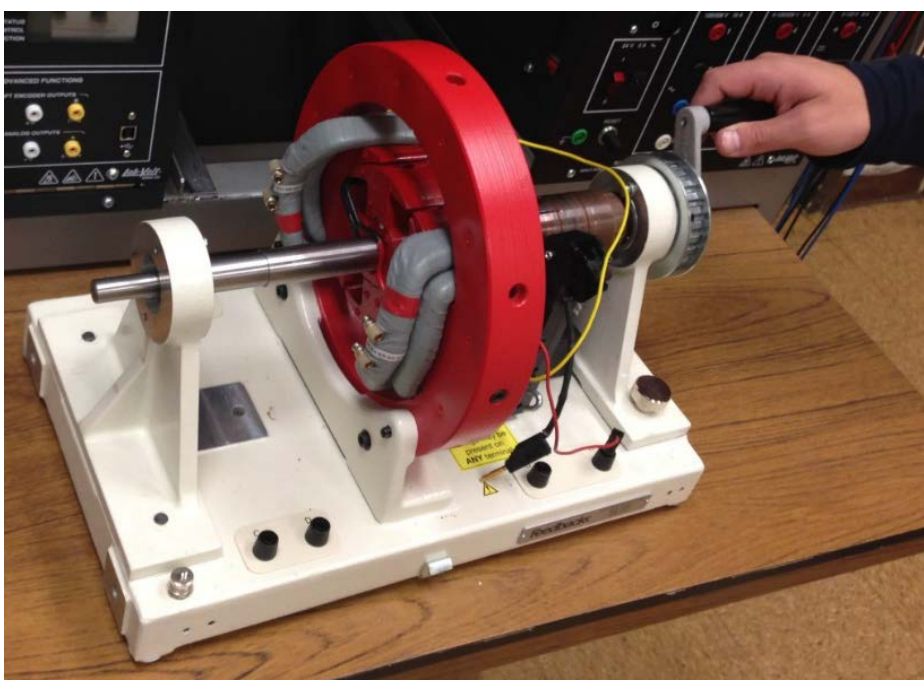

(c) Dissectible machine configured for a class demonstration about voltage induced on a rotating loop

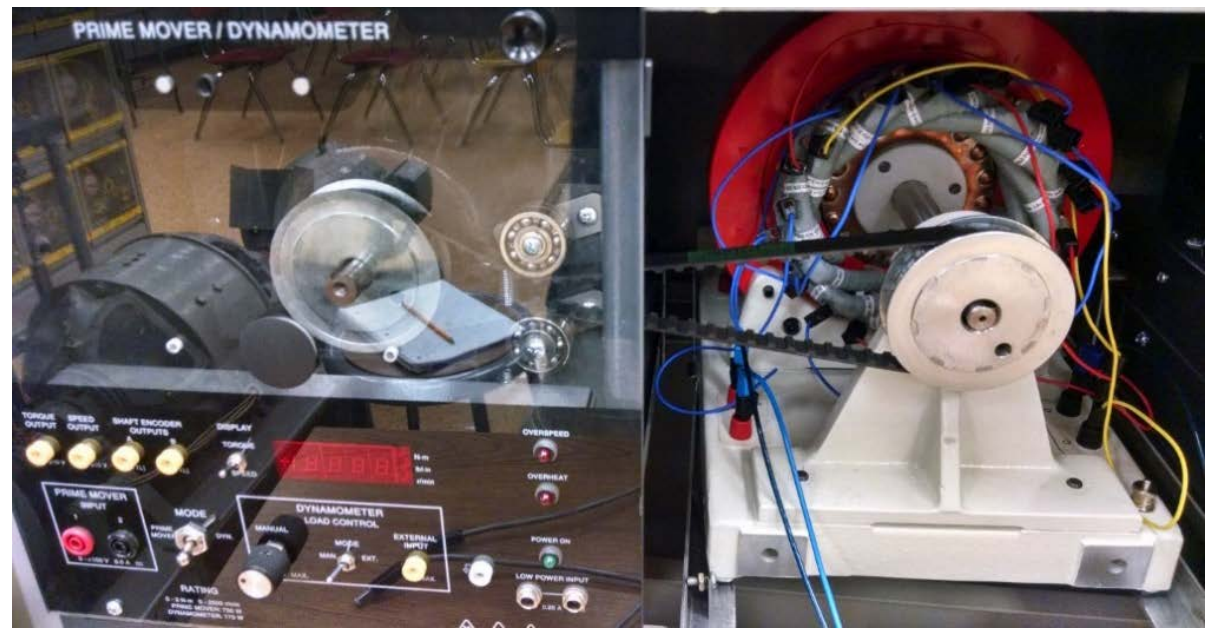

(d) Dissectible machine connected to the actuator via a belt for testing

Figure 4. Configurations of the Dissectible machine and integrated system 
Virginia NASA Space Grant Consortium Undergraduate Fellowship and presented his work at 14th Annual Undergraduate Research Day at the Capitol (Charleston, WV) on February 24, 2017.

This project is highly inter-disciplinary. It involves four faculty members of WVU Tech: Drs. Kenan Hatipoglu, Mingyu Lu, Yogendra Panta, and Afrin Naz. Dr. Kenan Hatipoglu’s expertise is in power electronics and power systems; the specialty of Dr. Mingyu Lu is electromagnetic field; Dr. Yogendra Panta is an expert of dynamic fluid mechanics and energy scavenging; and Dr. Afrin Naz has extensive experience on computer programming in assembly and high-level languages. Expertise of the four investigators is complementary to each other and covers all the aspects of this project. The four investigators are collaborating to build and improve the system, test the system, and integrate it with undergraduate curricula. This project therefore establishes an excellent platform for collaborative efforts among faculties and students from three departments, and it would inspire numerous innovative ideas across disciplinary boundaries.

\section{Conclusion / accomplishments}

After completing this project, the following accomplishments can be counted as the outcomes of this project. Mainly, an Integrated Electro-mechanical Energy Conversion System has been developed and constructed. It is physically located in Room 202 of Engineering Lab Building of WVU Tech campus. The final integrated electromechanical energy conversion system with all the required system components was put together on a Lab Station as seen in Figure 2. System was configured as DC and AC machine configurations for testing. Two undergraduate students were involved in this project as research assistants. Students worked closely with the faculty members in this project, and were trained by the faculty members in the areas of electromechanical energy conversion systems, electromagnetics / electrical measurements and power system and electronics control. Students gained practical research experience to become qualified engineers. In the future, the system will be made accessible to more students. The system has been integrated with curriculum and also been utilized for demonstrations in outreach activities. Since Fall 2016, the testbed has been used for proof of concepts in EE 335/336 (Electro-mechanical energy conversion system/Lab) and EE 435 (Introduction to Power Electronics) courses. So far, more than 30 undergraduate students used the system for experiments related to the courses and research. In addition, the integrated system was included in the Open House event held on November 10, 2016 at Leonard C. Nelson College of Engineering and Sciences of WVU Tech. Purpose of the event was to familiarize high and middle school students with cutting-edge technologies and to inspire them in science and engineering fields. Hundreds of students attended the event and had a chance to see the complete system. This project has enabled one grant proposal and several other grant proposals are in progress. 


\section{Bibliography}

1 Venkata, Subrahmanyam S. and E. Keith Stanek, Walton W. Cannon, and E.C. Dubbe. An Innovative Electric Power Curriculum at West Virginia University. Morgantown, [Online]. Available:

http://ieeexplore.ieee.org/stamp/stamp.jsp?tp=\&arnumber=4321234.

2 Kasten, Donald G. and Ali Keyhani, Stephen A. Sebo, and Neal A. Smith. Innovative Features in the Electric Power Program at the OHIO State University. Ohio State University. Columbus, [Online]. Available: http://ieeexplore.ieee.org/stamp/stamp.jsp?tp=\&arnumber=4112549.

3 Kulkarni, A.M. and B.G. Fernandes, S.V. Kulkarni, and S.A. Khaparde. Power Engineering Laboratories at IIT Bombay. Indian Institute of Technology, Bombay. India, [Online]. Available:

http://ieeexplore.ieee.org/stamp/stamp.jsp?arnumber=4596151.

4 Chowdhury, B. and B. Parkhideh, A. Martin, Z. Salami, J. Enslin, V. Cecchi, S. Kamalasadan, and N. Maciej. Enhancing power and energy systems concepts with laboratory experience. University of North Carolina at Charlotte. Charlotte, [Online]. Available:

http://ieeexplore.ieee.org/xpls/icp.jsp?arnumber=6672473.

5 Carr, Stephen G. Work in progress - cost-effective experiments for a first-course in electrical machine theory. Tri-State University. Angola, [Online]. Available: http://ieeexplore.ieee.org/xpls/icp.jsp?arnumber=4417865.

6 Dissectible Machines Tutor, Basic Components 62-100, Feedback Instruments Ltd, Available: http://www.google.com/url?sa=t\&rct=j\&q=\&esrc=s\&source=web\&cd=2\&ved=0ahUKEwib_7jV4_7RAhU B8WMKHbyKDYIQFgggMAE\&url=http\%3A\%2F\%2Fwww.feedbackinstruments.com\%2Fpdf\%2Fbrochures\%2F62005_datasheet_Dissectible_machine_08_2013.pdf\&usg=AFQjCNFyXWcXU2lEQ9rMCuhCltKkguBpxQ \&sig2=1N5nWsBLVRn7RuO3Odyq0w

7 Four-Quadrant Dynamometer/Power Supply, Model 8960-A0, Festo, LabVolt Series, Available: https://www.labvolt.com/solutions/6_electricity_and_new_energy/50-8960A0_four_quadrant dynamometer_power_supply_with_all function_sets

8 Data Acquisition and Control Interface, Model 9063, Festo, LabVolt Series, Available: https://www.labvolt.com/solutions/6_electricity_and_new_energy/98-906300 data acquisition and control interface

$9 \quad$ IGBT Chopper/Inverter, Model 8857-10, Festo, LabVolt Series, Available: https://www.labvolt.com/solutions/6 electricity and new_energy/50-8857-10_igbt_chopper_inverter Resistive Load, Model 8311-00, Festo, LabVolt Series, Available: https://www.labvolt.com/solutions/50-8311-00_resistive_load

11 Power Supply, Model 8821-20, Festo, LabVolt Series, Available: https://www.labvolt.com/solutions/6_electricity_and_new_energy/50-8821-20_power_supply 